\title{
The Role of Oral Communicative Tasks (OCT) in Developing the Spoken Proficiency of Engineering Students
}

\author{
S. Shantha (Corresponding author) \\ Department of Humanities and Social Sciences, National Institute of Technology, Tiruchirapalli, India \\ E-mail: shantha.ravi39@gmail.com \\ S. Mekala \\ Department of Humanities and Social Sciences National Institute of Technology, Tiruchirapalli, India \\ E-mail: mekala@nitt.edu
}

\author{
Doi:10.7575/aiac.alls.v.8n.2p.161 \\ URL: http://dx.doi.org/10.7575/aiac.alls.v.8n.2p.161
}

Received: 09/03/2017

Accepted: 25/04/2017

\begin{abstract}
The mastery of speaking skills in English has become a major requisite in engineering industry. Engineers are expected to possess speaking skills for executing their routine activities and career prospects. The article focuses on the experimental study conducted to improve English spoken proficiency of Indian engineering students using task-based approach. Tasks are activities that concentrates on the learners in providing the main context and focus for learning. Therefore, a task facilitates the learners to use language rather than to learn it. This article further explores the pivotal role played by the pedagogical intervention in enabling the learners to improve their speaking skill in L2. The participants of the study chosen for control and experimental group were first year civil engineering students comprising 38 in each group respectively. The vital tool used in the study is oral communicative tasks administered to the experimental group. The oral communicative tasks enabled the students to think and generate sentences on their own orally. The ' $t$ ' Test was computed to compare the performance of the students in control and experiment groups. The results of the statistical analysis revealed that there was a significant level of improvement in the oral proficiency of the experimental group.
\end{abstract}

Keywords: oral communicative tasks (OCT), pedagogical intervention, spoken proficiency, Task-based language teaching

\section{Introduction}

English language and communication skills are essential aspects of both individual and organizational success in the present era of globalization. Richards (2008) claims, "the mastery of speaking skill in English is a priority for many second-language or foreign language learners. Consequently, learners often evaluate their success in language learning as well as the effectiveness of their English course on the basic of how much they feel they have improved in their spoken language proficiency"(p.19). In engineering education, students need to acquire spoken proficiency in English as it is a significant requisite in their professional career. The work place situation necessitates engineers to acquire oral communication skills for conducting meetings, giving oral presentations, talking about every day assignments, participating in discussions, working in teams etc. (Reimer, 2007; Kaewpet, 2009; Kassim \& Ali, 2010). The prevailing situation is that the engineering students lack spoken proficiency in English, in spite of their long association with English language learning. Their insufficiency in spoken skill impedes them in their placement. ESL learners need to develop a repertoire to interact successfully in varied contexts with different people. More priority could be given to improve the spoken proficiency of students within the curriculum at the tertiary level as the primary objective for any higher learning institutions is to produce employable graduates. Zaremba (2006) indicates that speaking skills are regarded as one of the significant factors in seeking employment. According to many theorists like Nunan, Ur, speaking skills can be developed through communicative tasks. Tasks create interaction among the students thereby encouraging a conducive environment for language learning. In brief the ESL teacher should administer oral communicative tasks so as to enable the students to attain spoken proficiency in English. This study is experimented with first year civil engineering students of MAM College of Engineering and Technology located in Tamilnadu state, India. This article focuses on task-based approach in classroom teaching to improve the spoken proficiency of the ESL learners.

\section{Review of Literature}

\subsection{Speaking skill and Task-based language teaching(TBLT)}

The proficiency in speaking skill is the pertinent objective for any language learner. Bygate (1987) claims that learners are judged by their spoken proficiency. Speaking is a crucial part of language learning and teaching. Nunan (1991b) wrote, "Success is measured in terms of the ability to carry out a conversation in the (target) language" (p.39). Speaking 
is "the process of building and sharing meaning through the use of verbal and non- verbal symbols, in a variety of contexts"(Chaney,1998,p.13). Teaching speaking is not merely letting the students to repeat memorized dialogues, but they should be able to use the utterance to communicate in the real situation. Harmer (2001) states three basic reasons for administering speaking tasks to students in the classroom, firstly, speaking activities provide chances to rehearse the real life language use, secondly, speaking tasks provide feedback for both teacher and students and finally, they provide opportunities to the students to activate the various elements of language they have stored in their brains (p.87-88). A congenial environment needs to be created where the students come forward to perform a task along with their peers. TBLT is an effective approach where speaking skills are developed by performing a series of activities as steps towards successful task completion. TBLT has established its mark in fulfilling learners' needs and in providing opportunities for interactions in ESL context. A regular speaking task in the classroom can improve students' spoken proficiency. It requires teachers and students to be engaged in oral communicative tasks which will help them in real life situations.

\subsection{Task - based language teaching (TBLT)}

Ellis (2003 as cited in Douglas \& Kim, 2014) states that TBLT is an approach to language teaching that provides opportunities for students to engage in the authentic use of the target language through tasks. As the principal component in TBLT, the task provides the main context and focus for learning, and it encourages language use similar to the way language is used outside the classroom. Students learn language and develop skills as they work towards completing the task, which motivates them to stretch their available language resources. Thornbury (2007) opines that "a language is best learned through using it, rather than learned and then used" in task-based approach (p.119). Prabhu (1987) believes that students may learn more effectively, when they focus their minds on the task rather than on the language use. In recent years a number of researchers, theorists and educationists have expressed the need for TBLT approach in language teaching (Prabhu, 1987; Nunan, 1988; Ellis, 2003). Nunan (1991a) highlights five features of task-based approach as: an emphasis on learning through interaction in the target language, introducing authentic texts into the learning situation, providing opportunities for learners to focus not only on language but also on the learning process itself, enhancing learners own personal experiences as important contributing elements to classroom learning, and linking classroom language learning with language activities outside the classroom. Task-based approach focuses on communication and conveying message. It gives secondary importance to the forms used (Ellis, 2008, as cited in Ganta, 2015). Task-based language teaching encourages students to use English fluently and effectively. Norris (2009) points out those theoretical and empirical underpinnings for good teaching are integrated in TBLT with a due attention on learning outcomes in the form of "tasks". Cook (2008) indicates that in TBLT, learning and teaching should be planned around a set of communicative tasks and tasks are performed in the target language. Language learning does not happen without motivation, exposure and opportunities to use the language. Task-based learning encourages learners to use language purposefully. Task-based learning creates the right kind of an environment in enhancing the avenues of language learning spontaneously. It prepares learners to use language in the real world (Andon 2010, as cited in Ganta, 2015). Prabhu (1987) and Nunan (1988) consider TBLT as experiential learning. The learner acquires the language while actively involving in the experience of performing the tasks. It is experiential learning or learning by doing. Prabhu called his approach as 'Procedural Approach'. Language is seen as resource for communicating and not as a body of content to be memorized. Zhang (2009) states that ESL students usually have limited opportunities to speak English outside the classroom and hence the teachers must provide more situations and tasks for students to enhance their speaking skill. Teachers can use varied interesting strategies to develop the speaking skills. The classroom can be an effective and congenial environment to practise and improve the English speaking abilities of the learners.

\section{Need of the study}

Speaking skills are not given adequate priority to meet the communicative needs of the present day learners at the tertiary level. Due to this negligence, a substantial number of engineering students are graduating without acquiring the required spoken proficiency essential for their career. The significance of spoken proficiency is felt at the end of their engineering course i.e., while facing the interview panel during their placements. Some of them, who are not able to be placed in campus interviews, end up in joining Spoken English Courses after their graduation. More pathetic situation prevails in such Spoken English Institutes, as most of the time is spent on teaching fundamental grammar. Hence, there is a need to improve the speaking skills of these students during their graduation programme.

\subsection{Objective of the study}

The aim of any language teaching is to enable the learners to speak clearly, confidently, comprehensibly, and communicate with others using appropriate communicative strategies. In the Indian ESL context, with specific reference to engineering colleges, the onus of improving the spoken proficiency lies in the hands of the English teachers. This study paves way in enabling the ESL teachers to promote and upgrade the speaking skills of the engineering students using oral communicative tasks (OCT). The implementation of OCT will reduce the speaking constraints of the learners as they are exposed to English language in an interactive environment. This experimental study explores the possibilities of improving the spoken proficiency within the purview of engineering curriculum.

\section{Research Questions}

The focus of the present study is on the role of oral communicative tasks and their impact on the spoken proficiency of ESL students at tertiary level. The study addresses the following research questions.

1. How the OCT enabled the learners in developing the spoken proficiency of the learners?

2. What are the learners' and the teacher's constraints in the implementation of OCT? 
3. What is the impact of pedagogical intervention in developing the spoken proficiency of the learners?

\section{Method}

\subsection{The Design of the Study}

This research is a quasi-experimental study that seeks to investigate the effect of Task-based Instruction on engineering students to improve their oral proficiency. The study involves the implementation of oral communicative tasks to the participants in the control and experimental group. The study determines to explore the impact of administering of oral communicative tasks on the experimental group contrasting the control group. The role of pedagogical intervention is significant in implementing the tasks to the experimental group.

\subsection{Participants}

The participants of the study are first year B.E. students of Civil Engineering at M.A.M College of Engineering and Technology, Tiruchirapalli. The 76 participants were selected based on simple random sampling in which the samples were assigned to the control and experimental groups using lottery method. The control and experimental groups consist of 38 students each and their ages range between 17and19. The participants comprise 22 girls and 54 boys. Most of them are from the same background with regard to their first language, previous educational experience and learning context. Even though the participants studied English for around twelve years, they were lacking speaking skill in English. Besides, proficiency level of the students ranged from below average to good in their school final marksheet. Hence providing this kind of training will develop their spoken proficiency.

\subsection{Tools}

\subsubsection{Rationale of oral communicative tasks}

The oral communicative tasks are the primary instruments. Ellis (2003) states that tasks are tools for providing opportunities for learners to use the target language. The oral communicative tasks are designed to develop the spoken ability of the students. The objective of oral communicative tasks is to enable the students to think and generate sentences on their own. The purpose of assigning Icebreakers at the initial stage is to evoke interest of the learners in the tasks. The pre-task, Self-Introduction, aims to encourage the students to exchange information. In task-1 on Listing 10 activities of given professional, the students are expected to list out the activity of the given professionals in words and phrases. The objective of task-2 on Telling a list of five things is to enable the students to generate their to do's in similar pattern of sentences. The purpose of task-3 on Giving five associated ideas is to facilitate the students to think about an idea and generate sentences cohesively. Task- 4 on Situation Based Responses, prepares the students to anticipate and react in similar kind of real life situations. The objective of Long Answer Interview task is to capacitate the learners to create sentences logically and cohesively. The Comparing task is devised to enable the students to discuss the differences and similarities between the given two items and to get them familiarise with comparing and contrasting expressions. The task on Story completion is administered to bring out the creative and imaginative skills of the students. The objective of Role play is to provide a format for using elements of real life conversation and communication. The task on Group Discussion aims at educating the learners to address a particular problem or an issue, to produce a range of options or solutions, to demonstrate interpersonal and team skills. The objective of the Supporting task is to prepare the students for their active contribution of ideas in the core tasks. These objectives can be achieved through pedagogical intervention of the facilitator and continuous participation of the learners. The post-task on Impromptu speech aims at knowing how the students are able to deliver their thought process in a cohesive content fluently and confidently.

\subsubsection{Questionnaire}

A pre-study questionnaire was administered to the participants to know their demographic and academic details. A poststudy questionnaire was used as feedback to be collected at the end of the implementation of oral communicative tasks.

\subsubsection{Observation sheet}

The observation sheet was used to note down the students' performance of the tasks - their ability to perform the task, their choice of diction, their sentence construction, coherence in their utterence and correct pronunciation of words. At the end of each task completion the data from the observation sheet were transferred to the scoring sheet. The task performance was scored as per the analytical rubrics specified in the Common European Framework of Reference (CEFR).

\subsection{Scoring Rubrics}

The pre- and post-tasks and the task performances were assessed using the analytic parameters of spoken language scoring indicated by the Council of Europe (2001) in the Common European Framework of Reference (CEFR). It includes the assessing parameters such as fluency, Grammar, idea, volume and pronunciation. The assessment criteria and weightage of marks are tabulated. 
Table 1. CEFR Speaking Assessment criteria

\begin{tabular}{lc}
\hline Components Tested & Weightage of marks \\
\hline Fluency \& coherence & 4 marks \\
Grammatical Acceptability & 2 marks \\
Ability to expand the Idea & 1 mark \\
Volume & 2 marks \\
Pronunciation & 1 mark \\
Maximum Score & 10 marks \\
\hline
\end{tabular}

\subsection{Implementation}

76 first year Civil Engineering students in the control and experimental group participated in this study. SelfIntroduction was considered as pre-task and administered to the control group and experimental groups to note their entry level. In Self Introduction, almost all the students participated enthusiastically in the experimental group. The control group too performed well in the pre-task as it was an opportunity to acquaint with others and they came forward to perform with curiosity. Then the focus was shifted towards the experimental group. A schedule of 24 classes with 50 minutes duration spread over a period of 12 weeks was conducted to develop spoken proficiency of the learners. The experimental group of the study was given a general idea about the importance of developing speaking skills and to be fluent in English language as prospective engineers. They were also given a general idea about the program and its significance. The oral communicative tasks (OCT) were implemented to the experimental group. The tasks were assigned in a graded structure from simple to complex and this sequencing of tasks enabled the students to perform voluntarily. The control group was taught the syllabus specified by Anna University - Technical English (Code: H6152) course. Two ice breaker sessions were handled to the experimental group at the beginning of the OCT to prepare the learners to actively take part in the tasks. This was effective as the students participated voluntarily. The class session was continued further by letting the students answer to the questions asked in the activity.

For the first task on 10 activities of the given professional, the students were expected to list out the activities of the given professionals in words and phrases. The next task on Listing of five to do's- to save money, to look beautiful, etc. was done as group task. In the next task on Mentioning five associated ideas on facebook, Dream, etc. the learners seemed to be more confident and did not consider the negative evaluation of friends. They corrected their mistakes from the teacher's feedback. In Situation Based Responses most of the students used general terms such as 'sorry', 'congrats', 'excuse me', etc. Only a few responded appropriately. Long Answer Interview induced interest in the learners and they participated with excitement, despite their speaking constraints. It was generally observed that their anxiety level had reduced. Peer pressure and teacher's motivation influenced the slow learners to interact in the class. In the next task on Discussing the similarities and differences the students made a sincere attempt and many students showed steady improvement in delivering a coherent content. The duration of interaction also duly increased over a period of time. This task turned out to be interactive and the students voluntarily contributed their ideas as in the case of previous task. Story Completion elicited instantaneous interaction and girls interacted well. In the subsequent task on Role- play, though the students had a few grammatical errors, they were able to enact their roles skillfully. Pauses and fillers had reduced considerably. There was maximum participation in the following task on Group Discussion. The initiators of GD had an influence on reluctant performers. The post-task on Impromtu Speech was administered to both the control and experimental groups to perceive the difference in attainment of spoken proficiency. During the final task on Impromptu speech, there was a substantial improvement in the experimental group. The post-task was assigned to the control group and they felt reluctant. They were not able to perform the tasks, as they were not exposed to the nuances of content generation and delivery mechanism of speaking skill and strategic implication of oral communicative tasks.

\section{Data Analysis}

The qualitative and quantitative data were compiled from the administration of oral communicative tasks, Pre- and Posttasks. The quantitative analyses were devised using the Statistical Package for the Social Sciences (SPSS 17) and qualitative data was assigned from the observation sheets noted down by the researcher.

\subsection{Independent sample t-test for spoken components in pre-task}

Independent sample t-test was computed to compare the mean scores of each speaking component in the pre-task scores of the control and experimental groups. The mean and standard deviation of the scores of 76 participants are tabulated in table 2. 
Table 2. Independent sample t-test for spoken components in pre-task

\begin{tabular}{lcccccc}
\hline Test components & Group & $\mathbf{N}$ & Mean & Std.Deviation & T Value level of significance \\
\hline Fluency & Experiment & 38 & 1.3816 & 0.53819 & 0.480 & NS \\
& Control & 38 & 1.3158 & 0.65162 & & \\
Grammar & Experiment & 38 & 0.5921 & 0.19643 & 3.561 & 0.01 \\
& Control & 38 & 0.4474 & 0.15551 & & \\
Idea/content & Experiment & 38 & 0.5395 & 0.24333 & 1.209 & NS \\
& Control & 38 & 0.4737 & 0.23096 & & \\
Volume & Experiment & 38 & 0.7632 & 0.25300 & 4.825 & 0.01 \\
\multirow{5}{*}{ Pronunciation } & Control & 38 & 0.4868 & 0.24624 & & \\
& Experiment & 38 & 0.6053 & 0.20658 & 3.764 & 0.01 \\
Total & Control & 38 & 0.4474 & 0.15551 & & \\
& Experiment & 38 & 3.9079 & 1.01246 & 2.813 & 0.01 \\
& Control & 38 & 3.1579 & 1.29503 & & \\
\hline
\end{tabular}

The above table reveals that there is no significant difference observed between the control and experimental groups in terms of fluency and Idea/content in the pre-task score. They were not able to generate idea in the initial stage, as they were lacking in content. There is a significant difference between the groups in terms of Grammatical Ability, Volume, Pronunciation and Total score at .01 levels. The reason for this difference might be the reluctance of the control group in performing the pre-task. More over volume, pronunciation and grammar are considered as subsidiary parameters compared to the main scoring parameters such as fluency and content generation.

6.2 One-way ANOVA for Tasks' variables

In this study one- way ANOVA was carried out to find out the difference between the tasks performances of the experimental group with respect to the aspects of speaking components.

Table 3 One-way ANOVA for Tasks' variables

\begin{tabular}{lcccccc}
\hline $\begin{array}{l}\text { Speaking } \\
\text { components }\end{array}$ & tasks Sum of square & df & Mean square & F & Sig. \\
\hline Fluency & Between groups & 66.786 & 8 & 8.349 & 9.564 & 0.01 \\
& Within groups & 290.684 & 333 & 0.873 & & \\
& Total & 357.474 & 341 & & & \\
Grammar & Between group & 9.611 & 8 & 1.201 & 8.828 & 0.01 \\
& Within groups & 45.316 & 333 & 0.136 & & \\
& Total & 54.927 & 341 & & & \\
Idea/content & Between groups & 6.874 & 8 & 0.859 & 8.04 & 0.01 \\
& Within groups & 35.579 & 333 & 0.107 & & \\
& Total & 42.453 & 341 & & & \\
Volume & Between groups & 7.795 & 8 & 0.974 & 6.221 & 0.01 \\
& Within groups & 52.158 & 333 & 0.157 & & \\
& Total & 59.953 & 341 & & & \\
Pronunciation & Between groups & 4.870 & 8 & 0.609 & 6.208 & 0.01 \\
& Within groups & 32.651 & 333 & 0.098 & & \\
& Total & 37.521 & 341 & & &
\end{tabular}

The group mean of the variables was calculated and ' $F$ ' value was determined to find out whether there is any notable difference among the tasks performed by the experimental groups. Table 3 reveals that there is a significant variance among the tasks in terms of speaking components such as fluency, grammatical acceptability, ability to expand the idea, volume and pronunciation at .01 levels. 


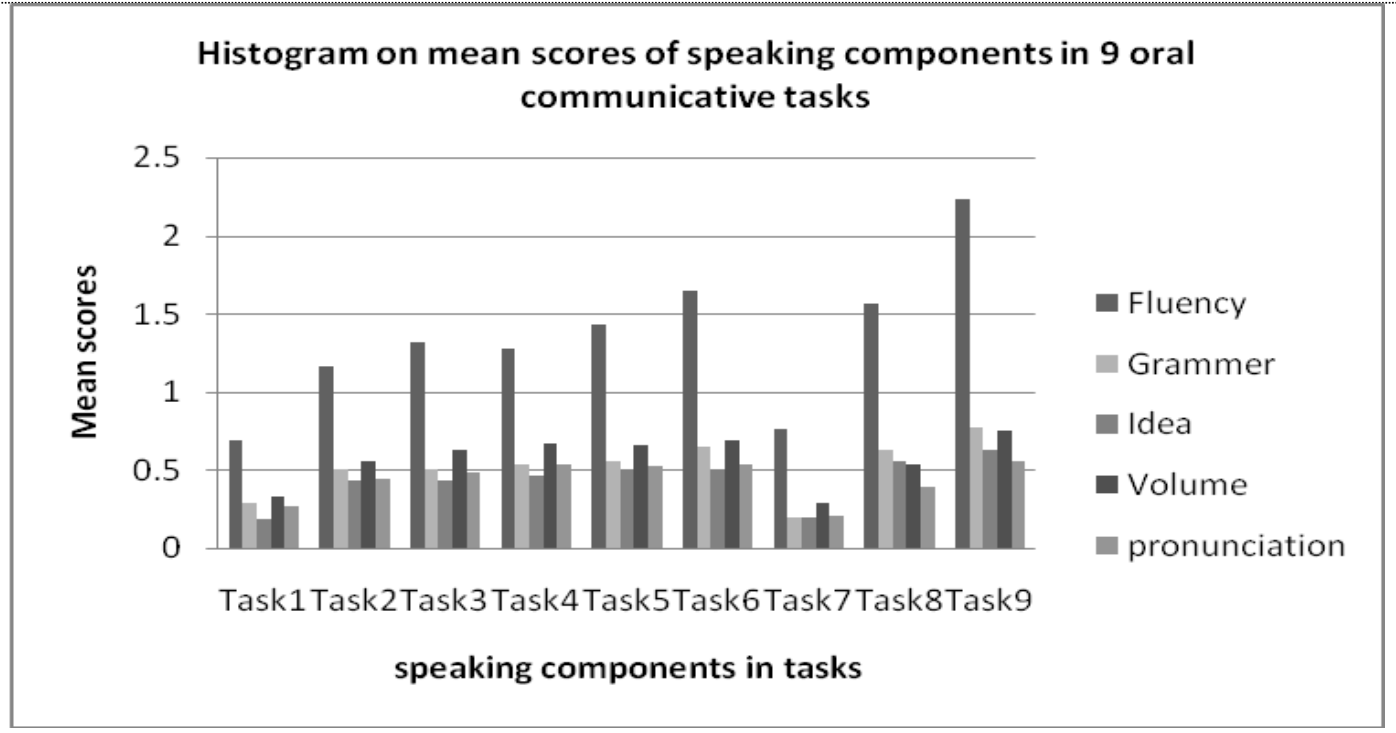

Figure 1. Histogram on mean scores of speaking components in 9 oral communicative tasks

The figure 1 indicates that there is a progressive raise in the mean scores of the nine tasks as the students improved gradually in their task performances. There is a decline in the histogram at the point of task-7 on Story completion, as the learners especially the boys were not able to be creative in composing a story and so the level of participation comparatively reduced in this task. However, in the subsequent task on Role-play there is a steady upward inclination in the histogram. The participation level of the learners consequently increased, as they were interested in assuming roles. Finally, in task-9 on Group Discussion, it can be observed that the chart shows the highest score, as the students were enthusiastic in participating in the Group Discussion.

6.3 Independent sample t-test for spoken components in post-task Independent sample t-test was computed to compare the mean scores of each speaking component in the post-task score of the control and experimental groups. The mean and standard deviation of the scores of the control and experimental groups are tabulated in the table 4 .

Table 4. Independent samples t-test for spoken components in post-task

\begin{tabular}{lcccccc}
\hline Test component & Group & $\mathbf{N}$ & Mean & Std.Deviation & T Value & Level of significance \\
\hline Fluency & Experiment & 38 & 2.2763 & 0.60065 & 7.451 & 0.01 \\
& Control & 38 & 1.1316 & 0.73231 & & \\
Grammar & Experiment & 38 & 0.9605 & 0.21377 & 10.173 & 0.01 \\
& Control & 38 & 0.4211 & 0.24372 & & \\
Idea/content & Experiment & 38 & 0.7237 & 0.2519 & 5.155 & 0.01 \\
& Control & 38 & 0.4079 & 0.28129 & & \\
Volume & Experiment & 38 & 0.8947 & 0.23704 & 6.00 & 0.01 \\
\multirow{2}{*}{ Pronunciation } & Control & 38 & 0.5000 & 0.32880 & & \\
\multirow{3}{*}{ Total } & Experiment & 38 & 0.7368 & 0.25300 & 6.083 & 0.01 \\
& Control & 38 & 0.3947 & 0.23704 & & \\
& Experiment & 38 & 5.6316 & 1.1251 & 8.463 & 0.01 \\
\hline
\end{tabular}

The above table reveals that there is a substantial difference between the control and experimental groups in the posttask score in terms of Fluency, Grammatical Ability, Idea/content, volume, pronunciation and Total score at .01 levels. It is obvious that experimental group has shown considerable improvement over the control group.

\section{Results and Discussion}

\subsection{Research Question 1.}

This study confirms that the students attained improvement in spoken proficiency after the implementation of OCT. The OCT was implemented in a regular classroom atmosphere by observing and recording students' progress, interacting and reflecting on various aspects of tasks and students' outcomes. In the beginning of each task, a demonstrative session was performed using volunteers. These demonstrative sessions enhanced the understanding of tasks by the learners and subdued their fears and inhibitions. In Self Introduction few felt interested in presenting themselves confidently in English and few students replicated others' performances. Some relied on the teacher's assistance in organising their thoughts in framing sentences. Most of the students perceived this activity to be a new experience for them. The students participated with involvement and expressed their ideas willingly in the two Ice breaker tasks. Many gave a long list of answers. Two teams came with 18 different uses of newspaper for the first task. A team came forward with 
40 words for the second task on forming words from given phrase, as this task made the students think and reason out the possibilities. The students initially took up the task on 10 activities of the given professional, later they searched for words and got struck in the middle. The teacher and peers prompted words so as to continue with the task. In performing the task on listing of five to do's the students prepared the answer by discussing with peers and seeking the help of the teacher. While a student presented the answer, others tried to contribute their ideas. This kind of interaction was encouraged and appreciated by the teacher. Their confidence level improved considerably in performing the subsequent tasks on Situation Based Responses, Long Answer interview etc. In the final task on Impromptu Speech, many tried to outperform other students by effortlessly participating in the task. Meticulous preparation using dictionaries exemplified their involvement in the task. It was evident that the negative factors like shyness, embarrassment and apprehensiveness had minimised in the due course. These tasks brought real life situations into the class, where students were provided with opportunities to express their ideas and exchange their opinions. In the due course, the students volunteered to participate in the tasks. The students could express their ideas freely because they performed the activities in pairs and groups with their peer group and the classroom naturally evolved into a learnercentred environment.

In the class of 38 students, a substantial number of 23 students have shown improvement in their spoken proficiency after attempting the oral communicative tasks. According to the data in the table 4, it is evident that the implementation of oral communicative tasks has proved to have developed the spoken performance of the experimental group and the experimental group had scored better than the control group in the post-task components. Willis (1996) states that "tasks are always activities where the target language is used by the learner for a communicative purpose (goal) in order to achieve an outcome" (p.23). Majority of the students aspired for more number of OCT sessions that exhibited their interest in the interactive learning environment. It is also important to highlight that some students were highly motivated in performing the tasks, since they perceived the significance of developing speaking skills in English and they had realized it as a pertinent requisite in their profession. Consequently, they actively took part in all the oral communicative tasks. The result of such active participation in tasks increased responses in the classroom environment and self and peer correction developed the oral proficiency of the learners in the due course. So it is confirmed that the implementation of oral communicative tasks with the aid of pedagogical intervention has enabled the experimental group to outperform the control group in their spoken proficiency.

\subsection{Research Question 2}

The experimental group faced many constraints in performing the OCT. Majority of the participants were first time speakers and were affected by their fear of failure. The stage fear prevented them from speaking and comprehending the prompting cues. The students could not practise and prepare for the tasks in the home environment due to lack of compatible sociolinguistic atmosphere and their inability to generate sentences in English on their own. The students who had Tamil medium schooling believed that they could not learn to speak in English and it was possible only for English medium students. As Jianing (2007) explains in her work "To protect them from being laughed at, the students are reluctant to speak English....the less they speak, the less they improve their speaking skills, and the more they are afraid of speaking" (p.1), another issue was the discouragement by peers. The students had fear of being insulted or teased when they tried to open a conversation in English with friends. Many found it difficult to convey a message or an idea. They seemed to be lacking in discourse ability of organising a thought. This was found to be a major impediment in their oral proficiency. They either produced half sentences in their speech or had false starts. They were unable to speak clearly and their voice level reduced due to their shyness, inhibition and lack of confidence. Some of them mumbled, left unnecessary and unnatural pauses in their speech, as they searched for the right word. Some used fillers like, aaah, uumm, and, I, etc. Some students avoided eye contact with the audience in their participation.

The teacher also faced some constraints in administering the oral communicative tasks to the experimental group. Norris (2009) points out that large class size, lesser contact hours, non-responsive students, exam-focused learning are the impediments in implementation of TBLT. The researcher found lesser contact hours and non-responsive students to be the challenges in the implementation of oral communicative tasks. Although the students are from the same background with regard to their first language, previous educational experience and learning context, considerable variations had been found in their spoken proficiency, say different levels of knowledge, skills, or expectations. The influencing factors were their educational, social, or cultural backgrounds. The language proficiency of the students varies as majority of the students were from regional medium schools and others from English medium schools. Even the English medium students lacked expected language proficiency. The time frame planned for the activities was not executed as the students did not prepare their home assignments in the tasks due to their inadequacies in English. As Willis (1996) claims that the noise level may raise in a large class as too much time has been allotted for a task and also it is not feasible to permit time for all the students to finish the task. The need to cover the syllabus and to keep pace with the rest of the topics/ portions mentioned in their course plan and to prepare the students for their periodical tests were to be considered. Although the importance of spoken proficiency in English was felt by the students, they seemed to be lacking interest in executing speaking activities as they would not be assessed in the end semester. They wanted to concentrate more time on exam-oriented exercises. The teacher cum researcher had to insist upon the significance of oral communicative activities and their utilitarian value for their career. The above said student and teacher constraints in implementing the OCT were addressed by the pedagogical intervention of the facilitator. The effective strategic implication was instrumental in overcoming the impediments. 
The pedagogical role was instrumental in this study in training the students to attain oral proficiency in English. The teacher took up many roles as Littlewood (1981) conceptualizes - facilitator of learning, who playes the sub roles as classroom manager, consultant, adviser and co-communicator with the students. The researcher cum facilitator in this study encouraged the students and motivated them to participate in the tasks. The students were made to interact with peers to overcome their constraints in speaking performance. Their participation increased their confidence level to make oral presentation. Yet some of the slow learners felt inhibited to participate in the class interaction and the facilitator paired them with enthusiastic proficient learners and shared the challenging tasks. Ellis (2003) points out that "It is not enough to simply put students into groups to complete a task. What counts is the quality of the interaction, and whether this enables students to engage effectively with the task and support each other's language learning" (p. 269). And the teacher played a crucial role in making this happen. The slow learners started to acquire the nuances of delivering content with logical progression of ideas. The facilitator enabled them to select the right word, structure a sentence, suggest an alternative word, and correct an ill-constructed sentence or their mispronunciation. The facilitator also helped the students to think in English. Patil (2008) states that the teacher should build up the learners' confidence to eliminate fear of making errors in order to make them feel at ease with their language use. The students were made to understand that errors were actually progressive evidence of their development in their learning process. The students were made to read aloud to overcome their pronunciation problems. The feedback provided by both the co-learners and the facilitator made the students understand to perform better in their subsequent oral tasks. At the end of each activity the facilitator gave feedback which made them feel that they accomplished a challenging task. The objective of teaching in this study was to develop speaking ability of the students and to facilitate the students to achieve language proficiency through interactive participation and performance.

\section{Conclusion}

This study was an attempt to improve the engineering students' spoken proficiency using oral communicative tasks. In the light of above discussion, it can be concluded that spoken proficiency of the engineering students can be improved using oral communicative tasks in the classroom. It is agreed that TBLT is particularly effective in enhancing the spoken proficiency of the learners when they are engaged in relatively similar real-life tasks. It is inferred from this study that administering oral communicative tasks in the class would benefit the learners to use English in real life situations as the interactions in the classroom are a simulation of a real life activities that would pave way for effective content generation and knowledge use. The effectiveness of the tasks implemented made the students realize their drawbacks in oral communication and improve their spoken proficiency. The result of the present study established that $61 \%$ of the students had shown substantial improvement. In a class of 38 students, 23 members participated in the oral tasks with involvement. The results overtly signified that the students can be made aware of their constraints and improve their speaking skills gradually by involving them in oral communicative tasks. This study has focused on one of the major impediments of engineering students' spoken component in the curriculum. This experimental study clearly indicates that the spoken proficiency of the students can be improved using OCT, and it also places emphasis on the significant role of English teachers in improving the language proficiency of their learners in ESL context.

\section{References}

Bygate, M. (1987). Speaking. In C Carter \& D. Nunan(Ed). The Cambridge guide to teaching English to speakers of other languages. Cambridge: Cambridge University Press.

Chaney, A. L. and Burk, T. L. (1998). Teaching Oral Communication in Grades K-8. Boston: Allyn \& Bacon.

Cook, V. (2008). Second Language Learning and Language Teaching (4th Ed..). London: Hodder Education \& Hachette UK Company.

Council of Europe (2001). Common European Frame work of References for languages: Learning, teaching, assessment. Cambridge: Cambridge University Press.

Douglas, S. R, and Kim, M. (2014). Task-based language teaching and English for academic purposes: An investigation into instructor perceptions and practice in the Canadian context. TESL Canada Journal, 31(8)

Ellis, R. (2003). Task-based Language Learning and Teaching. Oxford: Oxford University Press.

Harmer, J. (2001). How to teach English. Harlow: Pearson Education Limited.

Ganta, T.G. (2015). The strengths and weaknesses of Task-based learning (TBL) approach. Scholarly Research Journal for Interdisciplinary Studies. 3(16), 2760-2771.

Jianing, X.(2007). Storytelling in the EFL speaking classroom. The Internet TESL Journal. 13(11). Retrieved on April 10, 2010 from www.iteslj.org.

Kaewpet, C. (2009). Communication needs of Thai civil engineering students. English for Specific Purposes, 28(4), 266-278.

Kassim, H. and Ali, F. (2010). English communicative events and skills needed at the workplace: Feedback from the industry. English for Specific Purposes. 29(3), 168-182.

Littlewood, W. (1981).Communicative Language Teaching: An Introduction. Cambridge: Cambridge University Press. 
Norris, J. M. (2009). Task-based teaching and testing. In M. H. Long, \& C. J. Doughty (Eds.), The Handbook of Language Teaching. Oxford: Blackwell Publishing Ltd. 578-594.

Nunan, D. (1988). Syllabus Design. Oxford: Oxford University Press.

Nunan, D. (1991a). Communicative Tasks and the Language Curriculum. TESOL QUARTERLY, 15(2), 279-295.

Nunan, D. (1991b). Language Teaching Methodology: A Text Book for Teachers. New York: Prentice Hall

International Ltd.

Patil, Z.N. (2008). Rethinking the objectives of teaching English in Asia. Asian EFL Journal. 10 (4), 227- 240.

Prabhu, N .S. (1987). Second Language Pedagogy. Oxford: Oxford University Press.

Reimer, M. J. (2007). Communication Skills for the 21st Century Engineer. Global Journal of Engineering Education. 11(1), 89-100.

Richard, Jack C. (2008). Teaching Listening and Speaking: From Theory and Practice. Cambridge: Cambridge University Press.

Thornbury, S. 2007. How to Teach Speaking? Harlow: Pearson Education Limited.

Willis, J. (1996). A Framework for Task-based Learning. Harlow. UK: Longman Addison Wesley.

Zaremba, A. J. (2006). Speaking professionally. Canada: Thompson South-Western.

Zhang, Y. (2009). Reading to Speak: Integrating Oral Communication Skills. English Teaching Forum.47, (1) 32-34. Retrieved from http://files.eric.ed.gov/full text/EJ923446 pdf on 5.10.16. 